\title{
The Use of Taguchi Method to Elaborate Good ZnO Thin Films by Sol Gel Associated to Dip Coating
}

\author{
Modou Pilor ${ }^{1,2, *}$, Bouchaib Hartiti ${ }^{1}$, Alle Dioum ${ }^{3}$, Hicham Labrim ${ }^{4}$, Youssef Arba ${ }^{1}$, \\ Amine Belafhaili ${ }^{5}$, Mounia Tahri ${ }^{4}$, Salah Fadili ${ }^{1}$, Bassirou Ba ${ }^{2}$, Philippe Thevenin ${ }^{6}$ \\ ${ }^{1}$ ERDyS Laboratory/GMEEM \& DD Group, Hassan II University of Casablanca/Faculty of Science and Technique Mohammedia, \\ Casablanca, Morocco \\ ${ }^{2}$ LASES Laboratory, Cheikh Anta Diop University, Dakar, Senegal \\ ${ }^{3}$ Laboratory of Solid State Physics and Materials Science, Faculty of Sciences and Techniques, Cheikh Anta Diop University, Dakar, Senegal \\ ${ }^{4}$ Materials Sciences Unit/DRES/CNESTEN, Mohammed V University, Rabat, Morocco \\ ${ }^{5}$ Centre of Electron Microscopy, Faculty of Sciences, Mohammed V University, Rabat, Morocco \\ ${ }^{6}$ LMOPS, University of Lorraine, Metz, France
}

Email address:

pilormodou6@gmail.com (M. Pilor)

*Corresponding author

\section{To cite this article:}

Modou Pilor, Bouchaib Hartiti, Alle Dioum, Hicham Labrim, Youssef Arba, Amine Belafhaili, Mounia Tahri, Salah Fadili, Bassirou Ba, Philippe Thevenin. The Use of Taguchi Method to Elaborate Good ZnO Thin Films by Sol Gel Associated to Dip Coating. International Journal of Materials Science and Applications. Vol. 10, No. 1, 2021, pp. 18-24. doi: 10.11648/j.ijmsa.20211001.14

Received: February 16, 2021; Accepted: March 9, 2021; Published: March 17, 2021

\begin{abstract}
ZnO}$ thin films have been prepared by dip coating sol gel method using Taguchi technique. The underlying principle was to make something as little as conceivable the measure of examination and make sense of the best conditions for developing $\mathrm{ZnO}$ thin films with great properties. We used a trial plan of L9, with three levels (high, medium, low) and four elements (annealing temperature, precursor concentration, dip coating speed, annealing time). For each paper three sol-gel arrangements were arranged, and test is rehashed three time. We have chosen to carry out the optimization based on the gap energy calculated from the transmittance of the films obtained. Each sample was characterized with spectrophotometer. This characterization allowed us to draw the transmittance curve and to deduce the gap energy of each deposited $\mathrm{ZnO}$ thin film. A signal to noise and an analysis of variance (ANOVA) were used to determine the optical and electrical properties. The film that we obtained with the optimal condition was exanimated by using the characterization methods like UV-visible spectroscopy, X-ray diffraction, SEM (Scanning Electron Microscopy) and EDS (Energy Dispersive Spectroscopy). With the legal statement under oath condition, $\mathrm{ZnO}$ thin film showed high crystal quality and the transmittance is a greater amount of $90 \%$.
\end{abstract}

Keywords: Zinc Oxide (ZnO), Taguchi Method, ANOVA, Sol-gel, Dip Coating

\section{Introduction}

Zinc Oxide $(\mathrm{ZnO})$ is a sort of component used for make electronic circuits with a wide direct band gap of $3.37 \mathrm{eV}$. It has the characteristics of high exciton binding energy $(\sim 60 \mathrm{meV})$, noxiousness free, high electron mobility, and amazing piezoelectric conduct [1]. It is used in gas sensors [2], photodiode [3], solar cell [4], optical modulator waveguides [5], photonics crystals [6], varistors [7] etc.

$\mathrm{ZnO}$ thin films can be prepared by different technique such as Chemical bath deposition [8], sol-gel joined spin coating
[9], sol-gel process associated dip coating [10], spray pyrolysis [11], sputtering magnetron [12], electrodeposition [13], etc.

Among these methods, sol-gel is the most popular technique due to its simplicity and reliability of synthesis and reproducibility [14]. The basic component of this technique is to give an attractive thin film size and distribution at high return and low-cost preparation [15].

Consequently, the examinations using traditional trial strategies are inefficient. Therefore, advancement through test configuration is a successful method to limit the quantity 
of experiment, just as the expense of generation. Many plan of investigation approaches have been applied to improve the proficiency of synthesis procedures, for example BoxBehnken [16], Taguchi [17], D-optimal [18], Central Composite Design [19], etc.

Various research studies revealed that the Taguchi configuration is a perfect method in $\mathrm{ZnO}$ thin films synthesis [20-22]

The targets of this work are: (1) to apply the Taguchi robust design method on the enhancement of properties and to get the $\mathrm{ZnO}$ thin films by using ideal conditions and (2) to study the morphological, optical and structural properties of $\mathrm{ZnO}$ films deposited at the optimized conditions.

\section{Experimental Part}

\subsection{Preparation of Solutions}

The solution of $\mathrm{ZnO}$ sol-gel was prepared by dissolved zinc acetate dehydrate (ZAD) $\mathrm{Zn}\left(\mathrm{CH}_{3} \mathrm{COO}\right)_{2} 2 \mathrm{H}_{2} \mathrm{O}$ (Sigma
Aldrich 98\%) in $30 \mathrm{~mL}$ of isopropanol (ISOP) $\mathrm{C}_{3} \mathrm{H}_{8} \mathrm{O}$ (Merck) and monoethanolamine (MEA) like solvent and stabilizer respectively. The acquired sol-gel solution was then stirred under $75^{\circ} \mathrm{C}$ during $1 \mathrm{~h} 30$. The ratio MEA/ZAD is maintained 1:1. A homogeneous solution was obtained [23]. The solution was dip coated on glass substrates cleaned with distilled water and acetone. The pre-annealing temperature and time was fixed to $150^{\circ} \mathrm{C}$ and $10 \mathrm{mn}$, respectively. After each layer, the film was dried at $150^{\circ} \mathrm{C}$ for $10 \mathrm{mn}$ in a heater to vanish the dissolvable [24]. This operation is repeated 10 times (Figure 1). Each these samples were characterized by using UV-visible spectrophotometer in the range of 200-800 $\mathrm{nm}$. The sample prepared with an optimal combination of parameters has been characterized by using XRD with $\mathrm{CuK} \alpha$ radiation $(\lambda=0,154 \mathrm{~nm})$ in angle 2 theta ranging from 10 to $100^{\circ}$ at $0.02^{\circ}$ scanning rate to investigate the structural properties, EDS and SEM to study the morphological and compositional properties.

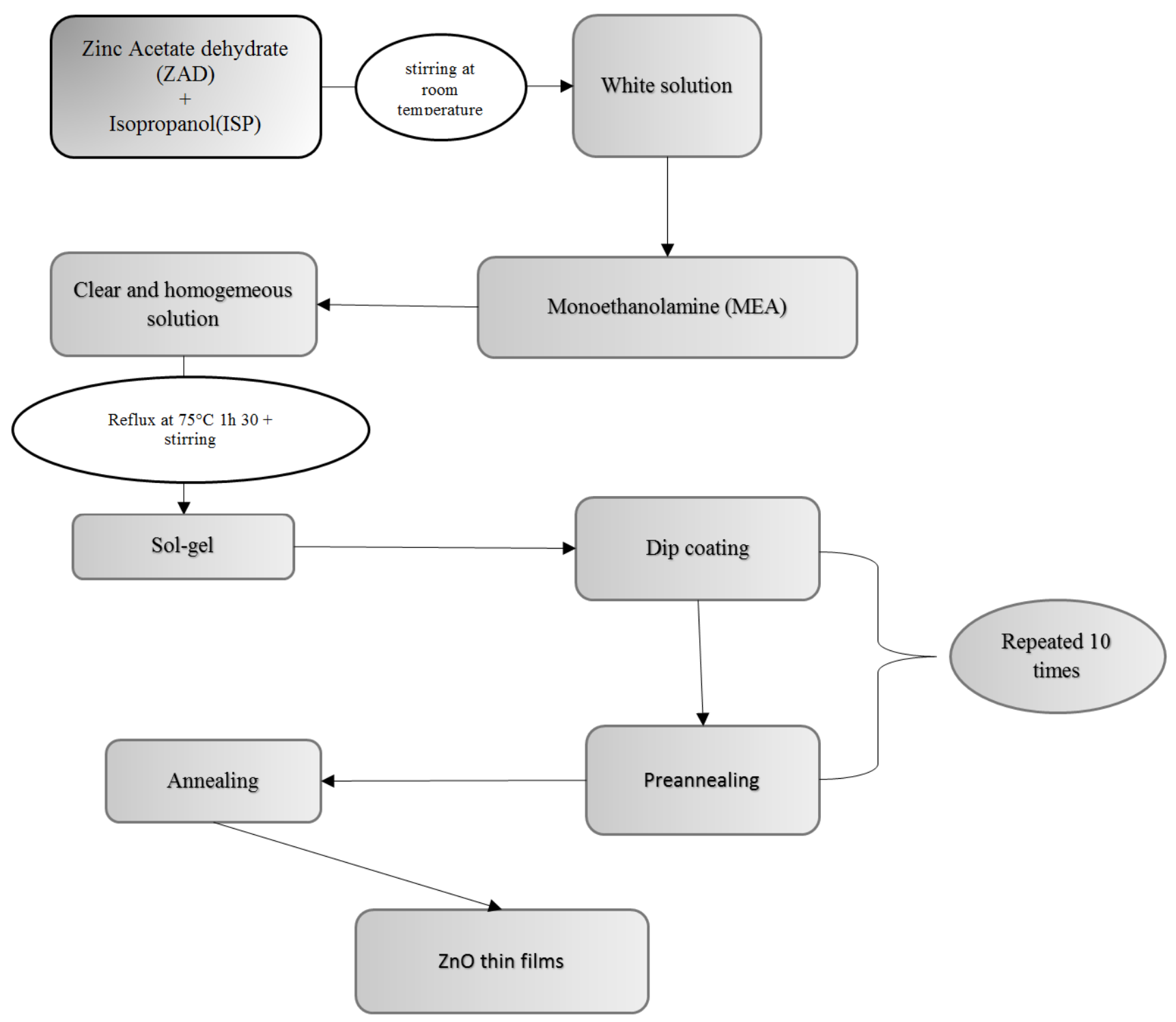

Figure 1. Preparation of sol-gel and thin films of $\mathrm{ZnO}$. 


\subsection{Design of Taguchi Approach}

Taguchi method is developed by Genichi Taguchi to improve the mechanical quality creation. This method studies two factors, the noise factor and the control factor. The difference accordingly is controlled by using $(\mathrm{S} / \mathrm{N})$ ratio and ANOVA is used to guess the error variance and figure out the role of each factor. [25]

We picked some factors ready to have significant influence on requiring reaction that we should improve as much as possible. Then, we have selected the appropriate experimental design to achieve the experiments.

L9 Taguchi table with orthogonal organized row was used to get the best limit conditions that give the optical band gap made by sol-gel method connected with dip-coating process. The optical band gap energy is a significant rule in photovoltaic devices. The limits are changed to decide the ability to change conditions for a best optical band gap of $\mathrm{ZnO}$ layer. Table 1 points to the different factors and their levels for the detailed $\mathrm{ZnO}$ thin films. Table 2 shows the combinations between these factors. Each experiment was repeated three times. The optimization of the best limits that gives a helpful band gap is based on the following equation (1) $[26]$

$$
\Delta E=\left|E_{t h}-E_{\text {exp }}\right|
$$

Where $\Delta \mathrm{Eg}$ is the difference between the best value $(3.37 \mathrm{eV})$ 3 [27] and experimental value of the band gap calculated from the transmittance spectra given by the experiments.

\subsection{Levels, Control Factors and Orthogonal Array}

The experiments were done with 4 control factors. These elements are grouping concentration of $\mathrm{Zn}\left(\mathrm{CH}_{3} \mathrm{COO}\right)_{2} 2 \mathrm{H}_{2} \mathrm{O}$, annealing temperature, annealing time and dip-coating speed. The levels of ZAD concentration were set on $0,25 \mathrm{~mol} / \mathrm{L}$, $0,50 \mathrm{~mol} / \mathrm{L}, 0,75 \mathrm{~mol} / \mathrm{L}$, annealing temperature on $450^{\circ} \mathrm{C}$, $500^{\circ} \mathrm{C}$ and $550^{\circ} \mathrm{C}$, annealing time on $60 \mathrm{mn}, 90 \mathrm{mn}, 120 \mathrm{mn}$, dip coating speed on $30 \mathrm{~mm} / \mathrm{mn}, 40 \mathrm{~mm} / \mathrm{mn}, 50 \mathrm{~mm} / \mathrm{mn}$. A L9 orthogonal organized row for 4 factors (each at 3 levels) was listed in Table 1. [28]

Table 1. Factors and levels.

\begin{tabular}{llll}
\hline & Low level & Medium level & High level \\
\hline Annealing temperature $\left({ }^{\circ} \mathrm{C}\right)$ & 450 & 500 & 550 \\
Precursor concentration $(\mathrm{mol} / \mathrm{L})$ & 0,25 & 0,50 & 0,75 \\
Annealing time $(\mathrm{mn})$ & 60 & 90 & 120 \\
Dip coating speed $(\mathrm{mm} / \mathrm{mn})$ & 30 & 40 & 50 \\
\hline
\end{tabular}

Table 2. L9 taguchi, Experimental values and the $S / N$ ratio.

\begin{tabular}{lllllllll}
\hline \multirow{2}{*}{ Experiments } & \multicolumn{2}{l}{ Control factors } & \multicolumn{2}{c}{ Sample 1 } & Sample 2 & Sample 3 & S/N ratio \\
\cline { 2 - 5 } & A & B & C & D & & & 0,17 & 13,37 \\
2 & A1 & B1 & C1 & D1 & 0,17 & 0,27 & 0,20 & 14,65 \\
3 & A1 & B2 & C2 & D2 & 0,22 & 0,12 & 0,14 & 17,83 \\
4 & A1 & B3 & C3 & D3 & 0,03 & 0,17 & 0,10 & 17,30 \\
5 & A2 & B1 & C2 & D3 & 0,13 & 0,13 & 0,22 & 13,36 \\
6 & A2 & B2 & C3 & D1 & 0,27 & 0,03 & 0,05 & 15,18 \\
7 & A2 & B3 & C1 & D2 & 0,22 & 0,08 & 0,17 & 16,71 \\
8 & A3 & B1 & C3 & D2 & 0,13 & 0,22 & 17,43 \\
9 & A3 & B2 & C1 & D3 & 0,07 & & & \\
\hline
\end{tabular}

\section{Results and Discussions}

To make the $\mathrm{S} / \mathrm{N}$ ratio analysis we used "the lower is better" according to the equation (2) to measure the thin films qualities. [29].

$$
\frac{S}{N}=-10 \log \left(\frac{1}{n} \sum_{1}^{n} Y_{i}^{2}\right)
$$

Where

$i$ is the number of an experiment, $\mathrm{n}$ the number of repeated experiments Yi represents the primary response
Table 3. Mean of S/N ratio.

\begin{tabular}{lllll}
\hline symbol & Level 1 & Level 2 & Level 3 & Optimal value \\
\hline A & 15,28 & 15,28 & 18,29 & A3 \\
B & 17,11 & 14,93 & 16,81 & B1 \\
C & 15,11 & 16,46 & 17,28 & C3 \\
D & 14,72 & 16,82 & 17,31 & D3 \\
\hline
\end{tabular}

Table 2 shows the experimental values of band gap energy and the $\mathrm{S} / \mathrm{N}$ ratio that it was calculated by the equation (2). The mean of the $\mathrm{S} / \mathrm{N}$ ratio for each level and the best value of each factor is shown in Table 3.

Figure 2 shows the mean of the $\mathrm{S} / \mathrm{N}$ ratios of all levels of factors and permit us to figure out the best conditions. The best value of each factor goes along with the maximum point in the curve [30]. The best condition is A3, B1, C3 and D3 


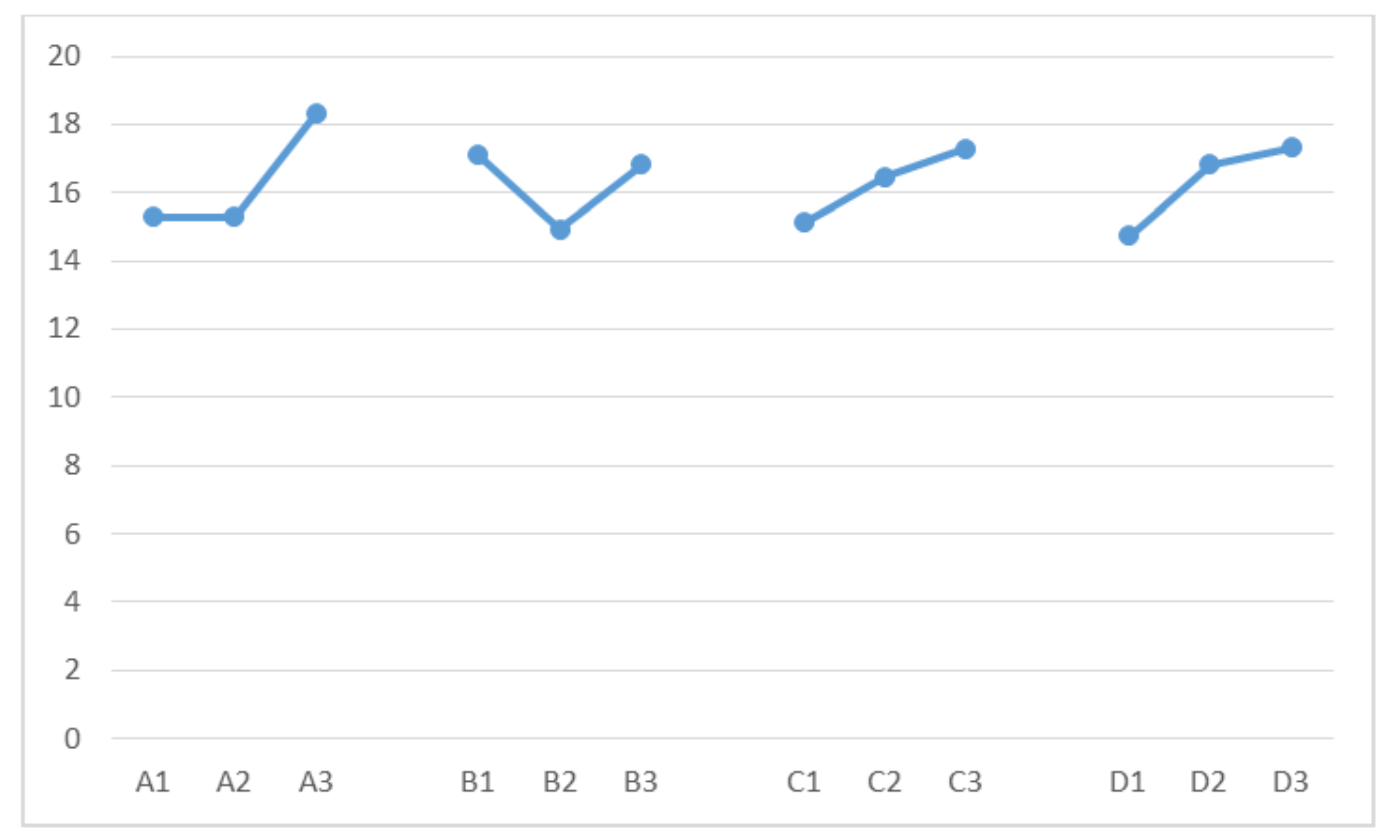

Figure 2. Graph of S/N ratio.

As per to the Figure 2, the annealing temperature is the most famous and important among the four factors. Then again, different components have pretty much equivalent impact.

\subsection{Description of the Films with Best Conditions}

From the results got by the analysis of variance, it was possible to decide the best conditions. The validation test was carried out by referring to the best conditions.

\subsection{Structural Properties}

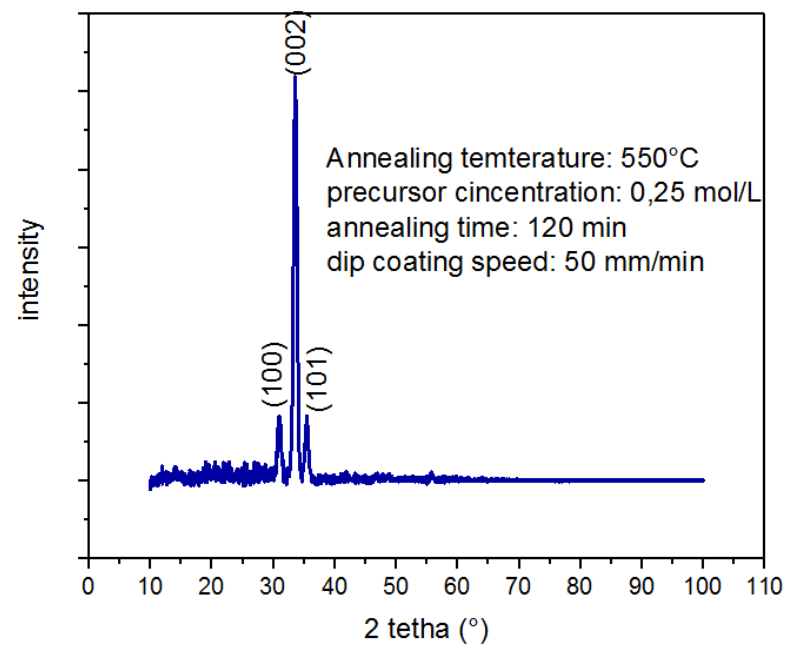

Figure 3. XRD pattern of $\mathrm{ZnO}$ thin film with best conditions.

The structural properties were obtained through XRD technique. Figure 3 shows the description of the $\mathrm{ZnO}$ thin film with the best conditions.

It has showed that the deposited film is polycrystalline with a six-sided wurtzite pattern. The diffraction peak result with best conditions (space group: P63mc (186); $\mathrm{a}=3,05$, $\mathrm{c}=5,30$ ) are in agreement with JCPDS for ZnO (JCPDS0361451). The good crystallinity is explained by the lowest surface energy density of the (002) plane of wurtzite crystal structure.

We can note that the film has a polycrystalline structure, with peaks positioned at $31.35,34.13$, and $35.60^{\circ}$ locations, matching up to the planes (100), (002), and (101), respectively. As shown in Figure 1, $\mathrm{ZnO}$ thin film has peak (002) as the preferred direction of pointing. [31]

The interplanar distance $d \mathrm{hkl}$ is calculated from the Bragg formula (Equation 3)

$$
2 d_{h k l} \sin \theta=n \lambda
$$

$\theta$ diffraction angle

$\mathrm{N}$ diffraction order

$\lambda$ wavelength

We calculated some parameters in the table 4 like the crystallite size (Dhkl), the dislocation (sigma), the lattice parameters a et c.

$$
\begin{gathered}
\frac{1}{d_{h k l}^{2}}=\frac{4}{3}\left(\frac{h^{2}+h k+k^{2}}{a^{2}}\right)+\frac{l^{2}}{c^{2}} \\
D_{h k l}=0,9 \frac{\lambda}{\beta \cos \theta}
\end{gathered}
$$

$$
\partial=\frac{1}{D_{h k l}^{2}}
$$

The wavelength of incident radiation is set to $0,154 \mathrm{~nm}$ and the lattice parameters ( $\mathrm{a}$ and $\mathrm{c}$ ) were calculated with the peaks (002) and (100). 
Table 4. Crystallite size, lattice constants, interplanar distance and dislocation density of ZnO thin film with optimal conditions calculated from the intense XRD peaks (002).

\begin{tabular}{|c|c|c|c|c|c|c|}
\hline experience & $\begin{array}{l}\text { Interplanar distance } d_{h k l} \\
(\mathrm{~nm})\end{array}$ & $\begin{array}{l}\text { Crystallite size D } \\
(\mathrm{nm})\end{array}$ & $\begin{array}{l}\text { Dislocation density } \\
\delta\left(10^{-4}\right)\end{array}$ & $\begin{array}{l}\text { Lattice parameter } \\
\mathbf{a}=\mathbf{b}\end{array}$ & $\begin{array}{l}\text { Lattice parameter } \\
\text { c }\end{array}$ & $\mathbf{c} / \mathbf{a}$ \\
\hline 1 & 0,257 & 13,15 & 57,82 & 2,96 & 5,14 & 1,73 \\
\hline 2 & 0,262 & 12,77 & 61,32 & 3,02 & 5,24 & 1,73 \\
\hline 3 & 0,268 & 11,25 & 79,01 & 3,09 & 5,36 & 1,73 \\
\hline 4 & 0,266 & 11,88 & 70,85 & 3,07 & 5,32 & 1,73 \\
\hline 5 & 0,265 & 11,12 & 80,87 & 3,05 & 5,30 & 1,73 \\
\hline 6 & 0,265 & 18,07 & 30,62 & 3,05 & 5,30 & 1,73 \\
\hline 7 & 0,264 & 12,58 & 63,18 & 3,04 & 5,28 & 1,73 \\
\hline 8 & 0,266 & 13,14 & 57,91 & 3,07 & 5,32 & 1,73 \\
\hline 9 & 0,265 & 12,95 & 59,62 & 3,05 & 5,30 & 1,73 \\
\hline
\end{tabular}

Table 4 shows different limits like the crystallite size (Dhkl), the dislocation (sigma), the lattice parameters a and c for a complete series of L9 Taguchi.

For each experiment the lattice limit is in agreement with JCPDS for ZnO (JCPDS036- 1451). The interplanar distance varies slightly.

The crystallite size (D) was calculated using the Scherrer's equation by selecting the most intense diffraction peak (101) (002).

The c/a calculated value for each experiment is significantly equal to 1,73 . This value is also in agreement with JCPDS for $\mathrm{ZnO}$

\subsection{Compositional and Morphological Properties}

Figure 4 shows a SEM image obtained from the manufactured thin film. It presents a group of elements that are the same in the surface. The study of the shapes elements

showed that we have got hexagonal structure. This surface morphological is dotted with grains of different sizes.

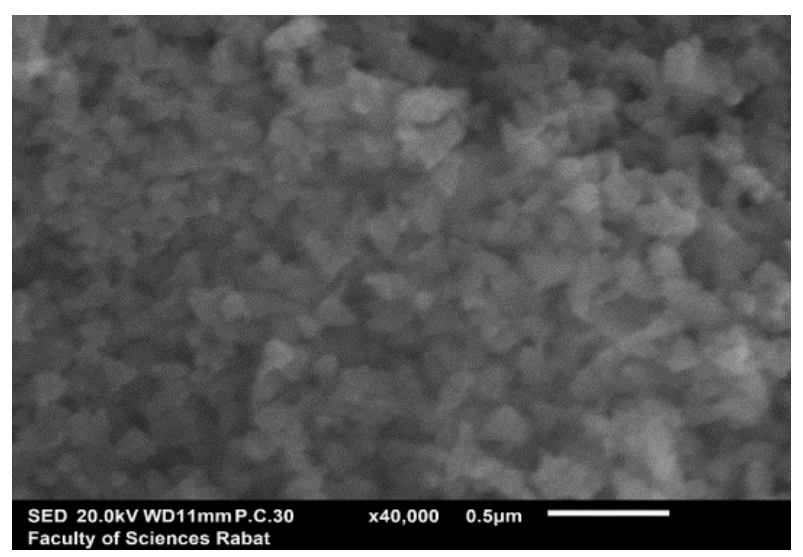

Figure 4. SEM image of the $\mathrm{ZnO}$ thin film with optimized conditions.

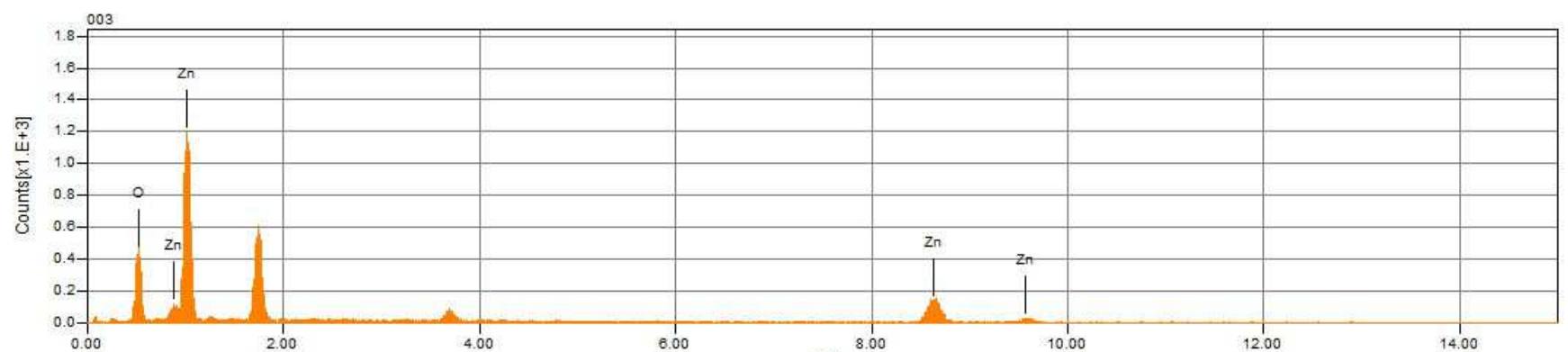

Figure 5. EDS of the ZnO thin film with optimized conditions.

Figure 5 shows the EDS of the $\mathrm{ZnO}$ thin film with muchimproved conditions. The peaks connected with the elements $\mathrm{Zn}$ and $\mathrm{O}$ are present. We can tell that other peaks of $\mathrm{Mg}, \mathrm{Al}$, $\mathrm{Si}$ and $\mathrm{Ca}$ are also present, but come from the supporting structure (substrate) on which the sample was deposited. Zinc and oxygen are in the proportions of $66,37 \%$ and $33,37 \%$ match up each pair items in order. [32]

Table 5. ZnO thin film composition deposited with best conditions.

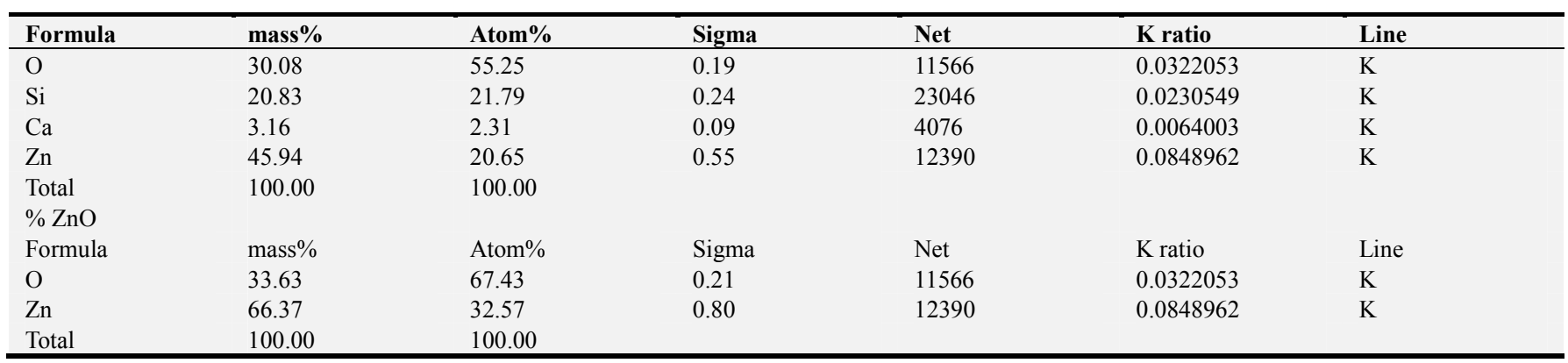




\subsection{Optical Properties}

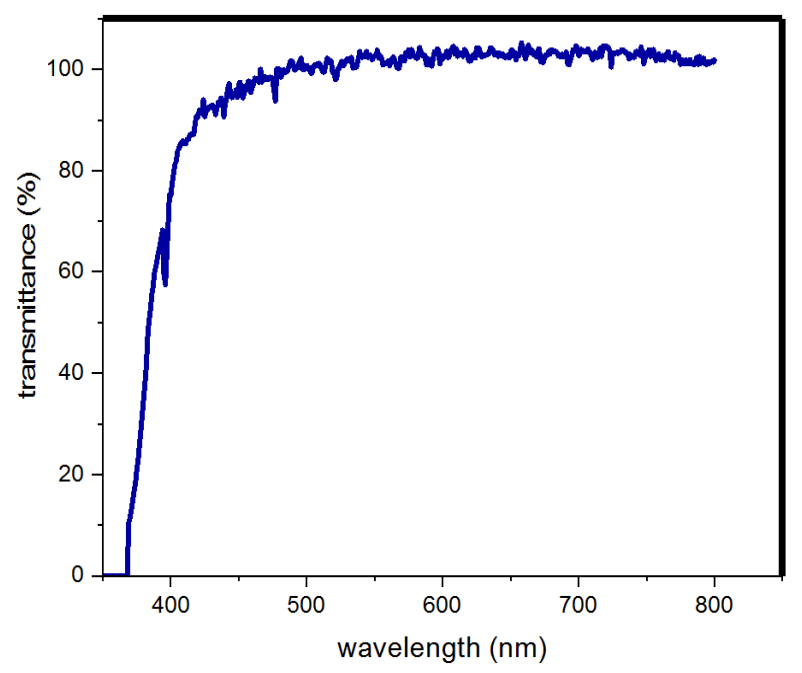

Figure 6. Transmittance of the $\mathrm{ZnO}$ thin film.

The transmission curve is represented in figure 6, we can calculate the direct band gap by the equation (7), which represents the difference of $(\alpha h v)^{2}$ with (hv)

$$
(\alpha h \vartheta)^{2}=B(h \vartheta-E g)=f(h \vartheta)
$$

B: constant

$h \vartheta$ : Energy of incident photons

Eg: Optical gap

The variations of $(\alpha h \vartheta)^{2}$ with energy (hv) are represented on the Figure 7. The optical gap is figure out by prediction of numbers, based on what's known of the curve $(\alpha h \vartheta)^{2}=\mathrm{f}(h \vartheta)$ at the value $(\alpha h \vartheta)^{2}=0$. The bandwidth is figure out from this equation, and represented by the value of the optical gap, rated $\mathrm{Eg}$ which is close to $3.25 \mathrm{eV}$. [33]

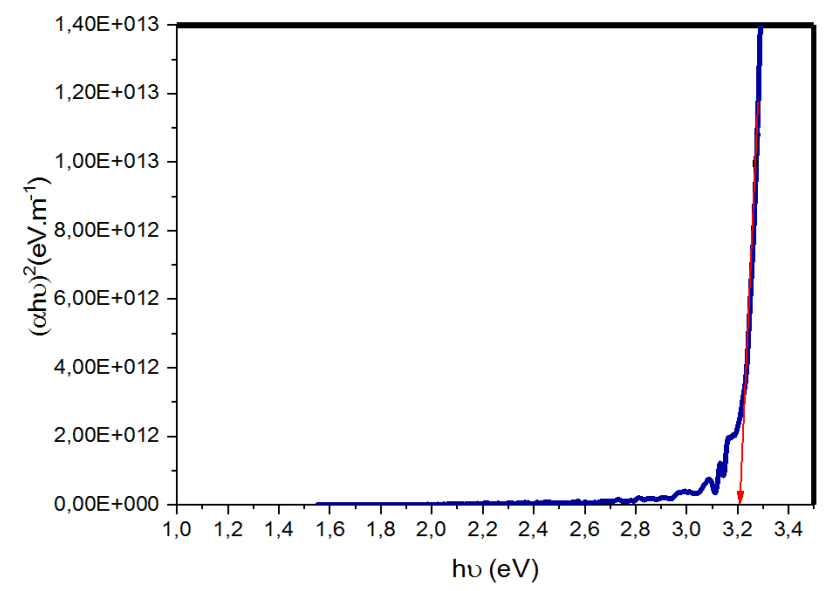

Figure 7. Determination of band gap energy.

\section{Conclusion}

The L9 Tagushi design was used to get the best limits for the creation of $\mathrm{ZnO}$ thin films.

The $\mathrm{S} / \mathrm{N}$ ratio analysis permit us to certify that the best limits are A1 B3 C4 D3. This combination is used to the validation test.

The structural, optical, morphological and compositional properties of sol-gel dip coated $\mathrm{ZnO}$ thin films by Taguchi method have been examined and it's closely to the reality can be found. The XRD spectra have showed that the films have the polycrystalline structure. The grain size of crystallites was in the range of 11-18 $\mathrm{nm}$. We have got 3,25 on optical band gap and all the films are highly clear with more than $90 \%$ in the visible area. The $\mathrm{ZnO}$ thin films can be used as a window layer in optoelectronic materials.

\section{Acknowledgements}

Prof. Bouchaib HARTITI, senior associate at ICTP (The Abdus Salam International Centre for Theoretical Physics), is very grateful to ICTP for financial support. Technical support from LMOPS (University of Lorraine, France) is also acknowledged.

\section{References}

[1] K. D. Kim, D. W. Choi, Y. H. Choa, H. T. Kim "Optimization of parameters for the synthesis of zinc oxide nanoparticles by Taguchi robust design method" Colloids and surfaces A, vol. 311, pp. 170-173, June 2007.

[2] P. Mitra, A. P. Chatterjee, H. S. Maiti (1997) $\mathrm{ZnO}$ thin film gas sensor, Materials Letters 35 (1998) 33-38.

[3] J. Y. Lee, Y. S. Choi, J. H. Kim, M. O. Park, S. Im Optimizing $\mathrm{n}-\mathrm{ZnO} / \mathrm{p}-\mathrm{Si}$ heterojunction for photodiode applications Thin solid Films 403-404 (2002) 553-557.

[4] Michael Gratzal, Dye-Sensitized Solid-state heterojunction solar cell www.mrs.org/pbmications/bulletin volume 302005 .

[5] M H Koch, P Y Timbrelland RN Lamb the influence of thin film cristallinty on coupling efficiency of $\mathrm{ZnO}$ optical modulator waveguides 1995.

[6] Yefan Chen, Darren Bagnall, Takafumi Yao ZnO as a novel photonic material for UV region Materials Science and Engineering B75 (2000) 190-198.

[7] Yuanhuan Lin, Zhongtai Zhang, Zilong Tang, Fangli Yuanand Jinlin Li Characterisation of $\mathrm{ZnO}$-based Varistore prepared from nanometer precursor powders Advanced Materials for Optics and Electronics Adc. Mater. Opt. Electron. 9, 205-209 (1999).

[8] Y. F Wang, J. H Yao, D. Jiaand H. Lei Optical prosperities of Ag-ZnO Composition nanofilms synthesized by Chemical bath deposition Acta Physica Polonia A (2010).

[9] Jin-Hong Lee, Kyung-Hee Ko, Byung-Ok Park Electrical and optical properties of $\mathrm{ZnO}$ transparent conducting films by solgel method Journal of Crystal Growth 247 (2003) 119-125.

[10] Zohra N. Kayani, Fareeha Naz, Saira Riaz, Shahzad Nassem Characteristics of $\mathrm{Al}$ doped $\mathrm{ZnO}: \mathrm{Ni}$ grown on glass substrate by sol-gel dip coating technique Journal of Saudi Chemical Society Volume 21, issue 4, May 2017 Pa bges 425-433. 
[11] F. Z. Bedia, A. Bedia, B. Ben youcef and S. Hamzaoui Electrical characterization of $\mathrm{n}-\mathrm{ZnO} / \mathrm{p}-\mathrm{Si}$ heterojunction prepared by spray pyrolysis technique Physics Procedia 55 (2014) 61-67 Eigth International Conference on Materials Sciences, CSM8-IS5.

[12] A. Ismail, M. J. Abdullah The structural and optical properties of $\mathrm{ZnO}$ thin films prepared at different RF sputtering power Journal of King Saud University-Science 2012.

[13] G. Panzeri, D. Muller, A. Accogli, E. Gilbertini, E. Mauri, F. Rossi, L. Nobili, L Magagn in Zinc electrodeposition fromachloride-freenon-acqueous solution based on ethyleneglycol and acetate salts Electrochimica Acta (2019).

[14] M. Nirmala, A. Anukaliani Structural and optical properties of an undoped and $\mathrm{Mn}$ doped $\mathrm{ZnO}$ nanocrystalline thin film Photonics Letters of Poland Vol. 2 (4) 189-191 (2010).

[15] E. Musavi, M. Khanlary, Z. Khak pour Red-orange photoluminescence emission of sol-gel dip-coatted prepared $\mathrm{ZnO}$ and $\mathrm{ZnO}: \mathrm{Al}$ nano-crystalline films Journal of Luminescence 216 (2019).

[16] Kamaluddeen Suleiman Kabo, Abdu Muhammad Bello and Ibrahim Rilwanu Yalwa Model development and optimization in methanolysis of ricebranoilusingnano crystalline $\mathrm{K}-\mathrm{ZnO}$ Catlyst: BOXBEHNKEN Design FUDMA Journal Of Science (FJS) vol. 3 No. 2, June, 2019 pp 103-114.

[17] Sho-Hwa Hu, Yi-Chuan Chen, Chyi-Ching Hwang, ChengHsiung Peng, Dah-Chuan Gong Analysis of growth parameters for hydrothermal synthesis of $\mathrm{ZnO}$ nanoparticles through a statistical experimental design method Springer Science (2010).

[18] Muneer M. Ba-Abbad, Abdul Amir H. Kadhum, Abu Bakar Mohamad Otimization of process parameters using D-optimal design for synthesis of $\mathrm{ZnO}$ nanoparticles via sol-gel technique Journal of industrial and Engineering Chemistry 19 (2013) 99-105.

[19] Fatemeh Ansari, Mehrorang Ghaedi, Mehdi Taghdiri, Arash Asfaram Application of $\mathrm{ZnO}$ loaded on activated carbon for ultrasonic assisted dyesremovel: Experimental design and derivative spectrophotometry method Ultrosonics Sonochemisry 33 (2016) 197-209.

[20] Tahmineh Movahedi, Reza Norouzbeigi Synthesis of flowerlike micro nano $\mathrm{ZnO}$ superhydrophobic surfaces: Additive effect optimization via designed experiments Journal of Alloys and Compounds 795 (2019) 483-492.

[21] Xiujuan Chen, Gordon Huang, Chunjiang An, Renfei Feng, Yinghui $\mathrm{Wu}$, Charley Huang Plasma-induced PAA-ZnO coated PVD Fmembrane foroily waste water treatment: preparation, optimization and characterization through Taguchi OA design and synchrotron-based X-ray analysis Journal of Membrane Science (2019).

[22] D. L. Zhu, Q. Wang, S. Han, W. J. Liu, F. Jia, Y. X. Zeng, X. C. Ma, Y. M. Lu Optimization of process $\mathrm{ZnO}$ thin films prepared by r.f. magnetron sputtering Applied Surface Science 298 (2014) 208-213.

[23] Zahira El Khalidi, Elisabetta Comini, Bouchaib Hartiti, Abderrahim Moumen, Hashitha M. M. Munasinghe Arachchige, Salah Fadili, Philippe Thevenin, Abderrafi Kamal Effect of vanadium doping $\mathrm{ZnO}$ sensing properties synthesized by spray pyrolysis Materials and Design 139 (2018) 56-64.

[24] Youssef Ammaih, Abderrazak Lfakir, Bouchaib Hartiti, Abderraouf Ridah, Philippe Thevenin, Meryane Siadat Structural, Optical and electrical properties of $\mathrm{ZnO}$ :Al thin films for optoelectronic applications. Opt Quant Electrà (2014) 46: 229-234.

[25] M Vanmathi, M Mohamed Ismail and Senthil Kumar Optimization of RF sputtering process parameters on electrical resistivity, deposition rate and sensitivity of Al-doped $\mathrm{ZnO}$ thin films grown on Si substrate using grey-Taguchi technique Bull. Mater. Sci (2019à) 42: 123.

[26] W Chebil, A. Fouzri, B. Azeza, N. Sakly, R. Mghaieth, A. Lusson and V. Saller Comparison of $\mathrm{ZnO}$ thin films on different substrates obtained by sol-gel process and deposited by spin-coating technique Indian Journal of Pure and Applied Physics.

[27] Sh. A. Mansour, F. Y Akuphanoglu Electrical-optical properties of nanofiber $\mathrm{ZnO}$ film grown by solgel method and fabrication of $\mathrm{ZnO} / \mathrm{p}$-Si heterojunction, Solid State Sciences 14 (2012) 121-126.

[28] Yong Xia, Libo Zhao, Yunyun Luo, Rahman Hebilul, Jiuhong Wang, Lei Li, Guoxi Luo, Xiangyang Zhou, Zhuang de Jiang Optimizing electrospinning-hydrothermal hybrid processon Taguchi method for modulation of point de fectsin $\mathrm{ZnO}$ micro/nano arrays towards photoelectronic application Journal of Alloys ad Compounds 779 (2019) 167-174.

[29] A. Ziti, B. Hartiti, H. Labrim, S. Fadili, M. Tahri, A. Belafhaili, A. Ridah, P. Thevenin, "Application of Taguchi method to optimize the sol-gel dip-coating process of the semiconductor Cu2ZnSnS4v with good optical properties" Journal of Sol-Gel Science and Technology, May 2019.

[30] C. Y. Hsu, T. F. Ko, Y. M. Huang Influence of buffer layer on AZO film properties by radio frequency magnetron sputtering Journal of the European Society 28 (2008) 3065-3070.

[31] Y. Ammaih, A. L fakir, B. Hartiti, A. Ridah, M. Siadat, and P. Thevenin, "Optimization of parameters for deposition of $\mathrm{ZnO}$ films by solgel using Taguchi method" Molecular Crystals and Liquid Crystals, VOL. 627, pp. 176-182, May 2016.

[32] Yasemin Caglar, Seval Aksoy, Saliha Ilican, Mujadat Caglar Crystalline structure and morphological properties undoped and Sn doped $\mathrm{ZnO}$ thin films Super lattices and Microstructures.

[33] K. F. Konan, B. Hartiti, B. Aka, A. Ridah, K. Dakhsi, Y. Arba et P. Thevenin Propriétés structurales et optiques de couches minces d'oxyde de zinc $(\mathrm{ZnO})$ textures $(002)$ par voie sol-gel via spin coating Afrique Sciences 06 (1) (2010) 29-37. 